\title{
Erratum to: Improving isopropanol tolerance and production of Clostridium beijerinckii DSM 6423 by random mutagenesis and genome shuffling
}

H. Máté de Gérando ${ }^{1,2} \cdot$ F. Fayolle-Guichard ${ }^{2} \cdot$ L. Rudant ${ }^{2} \cdot$ S. K. Millah ${ }^{1} \cdot$ F. Monot $^{2}$ •

N. Lopes Ferreira ${ }^{2}$ A. M. López-Contreras ${ }^{1}$

Published online: 15 September 2017

(C) Springer-Verlag GmbH Germany 2017

Erratum to: Appl Microbiol Biotechnol (2016) 100:5427-5436

https://doi.org/10.1007/s00253-016-7302-5

In the original publication of this paper, the author name was incorrectly presented in the html version.

Incorrect presentation: Ferreira N.L.

Correct presentation: Lopes Ferreira N

The original article has been corrected.

The online version of the original article can be found at doi: https://doi. org 10.1007/s00253-016-7302-5

N. Lopes Ferreira

Nicolas.lopes-ferreira@ifpen.fr

Food and Biobased Research Wageningen UR,

Wageningen, The Netherlands

2 Biotechnology Department, IFP Energies nouvelles,

Rueil-Malmaison, France 